Centre interuniversitaire de recherche

en économie quantitative

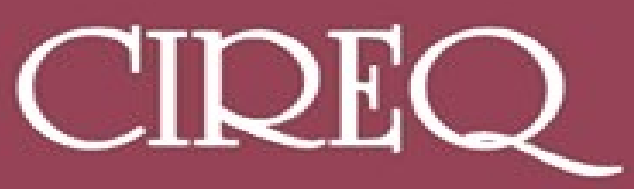

Cahier 14-2012

Some Effects of Asymmetries in a Common Pool Natural Resource Oligopoly

Hassan BENCHEKROUN, Gérard GAUDET and Hervé LOHOUES 


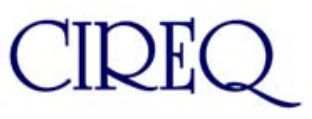

Le Centre interuniversitaire de recherche en économie quantitative (CIREQ) regroupe des chercheurs dans les domaines de l'économétrie, la théorie de la décision, la macroéconomie et les marchés financiers, la microéconomie appliquée et l'économie expérimentale ainsi que l'économie de l'environnement et des ressources naturelles. Ils proviennent principalement des universités de Montréal, McGill et Concordia. Le CIREQ offre un milieu dynamique de recherche en économie quantitative grâce au grand nombre d'activités qu'il organise (séminaires, ateliers, colloques) et de collaborateurs qu'il reçoit chaque année.

The Center for Interuniversity Research in Quantitative Economics (CIREQ) regroups researchers in the fields of econometrics, decision theory, macroeconomics and financial markets, applied microeconomics and experimental economics, and environmental and natural resources economics. They come mainly from the Université de Montréal, McGill University and Concordia University. CIREQ offers a dynamic environment of research in quantitative economics thanks to the large number of activities that it organizes (seminars, workshops, conferences) and to the visitors it receives every year.

Cahier 14-2012

\title{
Some Effects of Asymmetries in a Common Pool Natural Resource Oligopoly
}

\author{
Hassan BENCHEKROUN, Gérard GAUDET and \\ Hervé LOHOUES
}

CIREQ, Université de Montréal C.P. 6128, succursale Centre-ville Montréal (Québec) H3C 3J7 Canada
Université th de Montréa
McGill

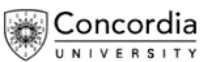


Ce cahier a également été publié par le Département de sciences économiques de l'Université de Montréal sous le numéro (2012-11).

This working paper was also published by the Department of Economics of the University of Montreal under number (2012-11).

Dépôt légal - Bibliothèque nationale du Canada, 2012, ISSN 0821-4441

Dépôt légal - Bibliothèque et Archives nationales du Québec, 2012

ISBN-13 : 978-2-89382-636-3 


\title{
Some Effects of Asymmetries in a Common Pool Natural Resource Oligopoly
}

\author{
Hassan Benchekroun \\ Department of Economics and CIREQ \\ McGill University \\ Gérard Gaudet \\ Département de sciences économiques and CIREQ \\ Université de Montréal \\ Hervé Lohoues \\ Macroeconomic Policy Department \\ ECOWAS Commission
}

August 2012 


\begin{abstract}
We consider a renewable resource being exploited in common by firms that compete both in the output market and in the exploitation of the resource. We show that the introduction of the slightest cost differentiation among the firms can have a drastic effect on the nature of the equilibria that may be expected as compared to the identical cost case. To do this, we take as a benchmark case a Markov Perfect Nash Equilibrium that exists with identical cost firms, with the property that the firms play a linear strategy up to some endogenously determined threshold level of the stock and the static Cournot equilibrium strategy beyond that threshold. Having shown that an equilibrium of that nature is not sustainable with asymmetric cost, we fully characterize a Markov Perfect Nash Equilibrium of the differential game for that case.
\end{abstract}

\title{
Résumé
}

Nous envisageons le cas d'une ressource naturelle renouvelable exploitée en commun par des firmes qui se concurrencent à la fois dans le marché du produit et dans l'exploitation de la ressource. Nous montrons que l'introduction de la moindre différence de coûts entre les firmes peut avoir un effet drastique sur la nature de l'équilibre, à comparer avec le cas de coûts identiques. Pour ce faire, nous prenons comme point de référence un équilibre de Nash markovien parfait qui existe dans le cas de firmes identiques et qui a la propriété que les firmes jouent une stratégie linéaire jusqu'à une borne supérieure endogène du stock et la stratégie correspondant à l'équilibre de Cournot statique au-delà de cette borne. Après avoir montré qu'un équilibre de cette nature n'est pas soutenable avec des coûts asymétriques, nous proposons une caractérisation complète d'un équilibre de Nash markovien parfait au jeu différentiel correspondant à ce cas. 


\section{Introduction}

Studies of the economic dynamics of common pool resource exploitation typically assume that the economic agents exploiting the resource are all identical. Yet, in many situations, the heterogeneity of the agents is an inescapable characteristic of the problem. Think for example of the case of fisheries, where it is common to find a number of big multinational fishing firms competing with many small local fishermen for the exploitation of a common fishing ground. These big firms have access to large scale technologies and consequently face considerably lower marginal costs than the small local fishermen. Similarly, aquifers are often shared by a few large capacity users — for instance big bottling firms — and many small capacity users. ${ }^{1}$ In such cases, it seems important to take into account the heterogeneity of the agents in order to properly characterize the non-cooperative equilibria. It is the purpose of this paper to introduce some form of heterogeneity into a common pool resource model and to analyze the impact of this heterogeneity on the equilibrium outcome of the dynamic game being played by the agents. The emphasis is put on how the slightest heterogeneity can have a drastic effect on the type of equilibria that can be expected, as compared to the homogeneous agents case.

More precisely, we consider the exploitation of a renewable resource stock by a finite number of two types of agents: a low marginal cost type, which we will call the "big firms" for short, and a high marginal cost type, which we will call the "small firms". The total number of firms, which we will assume fixed, will thus be divided into two groups of firms, identical within groups but different across groups. The situation will be modeled as an oligopolistic differential game in which the two groups of firms have access to the same renewable natural resource pool, which they exploit in common. They then sell their harvest on the same output market. They are therefore competing both in the output market and in the exploitation of the common pool resource. We restrict attention to non-cooperative equilibria in stationary Markov strategies, that is decision rules that are contingent only on

\footnotetext{
${ }^{1}$ The prevalence of asymmetries is well illustrated in Ostrom and Gardner (1993). Their purpose and approach are however quite different from ours; they are interested in the emergence through bargaining of institutions to manage the commons in the face of heterogeneous agents.
} 
the current state of the game. In our context, those decision rules specify the firm's resource extraction rate as a function of the current stock of the resource.

A number of authors have analyzed the problem of the exploitation of a common pool resource in a differential game framework. Amongst them, Levhari and Mirman (1980), Clemhout and Wan (1985), Plourde and Yeung (1989), Fischer and Mirman (1992, 1996), Dockner and Sorger (1996), Dockner et al. (2000), Gaudet and Lohoues (2008), consider cases where the agents involved compete for the exploitation of the resource, but do not compete on the output market. In those papers, the benefit functions of the agents depend only on their own production, not on that of their rivals. In this paper, the agents compete in the output market as well as in the exploitation of the resource, as in Benchekroun (2003, 2008), Karp (1992) and Mason and Polasky (1997). As in this paper, those authors assume benefit functions that depend not only on the agents' own production, but also, through the output market, on the production of their rivals. However, they assume identical agents when comes the time to derive equilibrium strategies. We will allow for heterogeneous agents.

Our model is closely related to the identical-agents model of Benchekroun (2003, 2008), which we take as a point of comparison to illustrate equilibrium impacts of heterogeneity. As in Benchekroun (2003, 2008), we consider a renewable natural resource characterized by a concave growth function which is approximated by two linear segments, and we assume that all the firms sell the product of their harvest on the same output market, characterized by a downward sloping linear demand function. Benchekroun (2003) assumes two identical players exploiting the resource at zero marginal cost and focuses on the effects on the equilibrium resource stock of a unilateral restriction of the exploitation of one firm and the corresponding adjustment in the rival's exploitation. Benchekroun (2008) assumes a finite number of firms and determines the impact of a change in the implicit growth rate of the resource on firms' extraction and profits. We assume a finite number of firms split into two groups and differentiated by their marginal costs. We focus on the effects of the cost asymmetry on the individual equilibrium strategies and the aggregate harvest rate.

In Benchekroun (2003), it is shown that there exists a Markov Perfect Nash Equilibrium 
(MPNE) with the following characteristics: below some initial threshold level of the resource stock, the resource is not harvested at all, hence allowing the resource to grow; follows an interval of the stock, up to some second threshold, over which each firm's harvesting decision is a linear and increasing function of the resource stock; beyond that last threshold, each firm's harvest rate is a constant that corresponds to the static Cournot equilibrium.

We will see that cost asymmetry has a drastic effect on this type of equilibrium: there cannot exist, as in Benchekroun (2003, 2008), a MPNE with the characteristic that linear strategies are played over some interval, followed by the firms playing the static Cournot equilibrium. This leads us to conclude that if there exits a MPNE which is such that beyond some high enough level of the stock the Cournot static equilibrium is to be played, it must be the case that non linear strategies are played in the preceding stock interval.

However, there does exist a MPNE where linear strategies are played over some interval of the stock, with the upper bound of the interval being maintained by an impulse control on the part of the high marginal cost firms. This means that stocks higher than this upper bound will not be sustainable in this equilibrium. Such an equilibrium also differs from the identical firms equilibrium of Benchekroun (2003) by the fact that the interval characterized by linear strategies is preceded by two subintervals: one where no harvesting takes place and one where only the low marginal cost firms produce. There may of course also exist other MPNE such that linear strategies are played over some interval of the stock, while higher stock levels remain sustainable.

In the next section, we present the model. We then characterize a MPNE in Section 3, while emphasizing how the presence of cost asymmetries rules an equilibrium of the same nature as that found in the benchmark case of identical firms. Section 4 offers concluding remarks.

\section{The model}

Consider a natural resource that is commonly owned and exploited by $n$ firms divided into two groups: a group of $n_{b}$ "big" firms and a group of $n_{s}$ "small" firms, with $n_{s}+n_{b}=n$. 
They are identical within a group but differ between groups by their (constant) marginal costs. The representative member from a given group $i, i=s, b$, has a marginal cost $w_{i}$. We will assume that

\section{Assumption 1: $\quad w_{s}>w_{b}$.}

Hence the big firms have a cost advantage over the small firms, which bear a greater marginal cost.

Denote by $x(t)$ the stock of the resource at time $t$ and by $q_{k}(t)$ the rate of harvest of a given firm $k, k=1, \ldots, n$. The inverse demand function for the output is

$$
P(Q)=a-b Q
$$

where $a$ and $b$ are two positive constants. We assume that $a-w_{i}>0, i=s, b$.

As in Benchekroun (2003), we assume that the natural growth function of the resource takes the form

$$
g(x)= \begin{cases}\delta x & \text { for } x \leq k / 2 \\ \delta(k-x) & \text { for } x>k / 2\end{cases}
$$

where $\delta$ and $k$ are positive parameters reflecting the characteristics of the ecosystem. The parameter $\delta$ represents the intrinsic growth rate of the resource, while the parameter $k$ represents the carrying capacity of the ecosystem.

We assume that the intrinsic growth rate of the resource satisfies

$$
\text { Assumption 2: (i) } \delta>\frac{\left(n^{2}+1\right) r}{2} \text { and (ii) } \delta \geq \frac{2\left(n^{2}+1\right)\left(a-w_{b}\right)}{(n+1)^{2} b k} \text {, }
$$

where $r$ is the discount rate, assumed the same for all the firms. The assumption in (i) that $\delta / r$ is strictly bounded from below serves to guarantee the existence of a strictly interior equilibrium steady-state stock. It is common in the literature (see for instance Benchekroun 
(2003), Dockner and Sorger (1996) or Dutta and Sundaram (1993a,b)). As for the assumption in (ii), it is made to simplify the exposition, as will be explained shortly (on page 8 ). ${ }^{2}$

We restrict attention to equilibria in stationary Markov strategies. Stationary Markov strategies in this context are decision rules that specify a firm's harvest rate as a function of the current resource stock: $q_{k}(t)=\phi_{k}(x(t))$. Firm $k, k=1, \ldots, n$, takes the strategies of its $(n-1)$ rivals as given in choosing its own decision rule, $q_{k}=\phi_{k}(x)$ in order to maximize the present value of its flow of instantaneous profits:

$$
J_{k}=\int_{0}^{\infty} e^{-r t}\left\{\left[P\left(q_{k}+\sum_{l \neq k} \phi_{l}(x)\right)-w_{k}\right] q_{k}\right\} d t
$$

subject to

$$
\dot{x}=g(x)-q_{k}-\sum_{l \neq k} \phi_{l}(x)
$$

and

$$
q_{k} \geq 0, \quad \lim _{t \rightarrow \infty} x(t) \geq 0
$$

We are looking for a Markov Perfect Nash Equilibrium (MPNE). An $n$-tuple of stationary Markov strategies $\left(\phi_{1}(x), \ldots, \phi_{n}(x)\right)$ constitutes a MPNE of this dynamic game if, for every possible initial condition $x(0)=x_{0}$, it simultaneously solves the above problem for $k=$ $1,2, \ldots, n$. Since we have two groups of firms and firms are identical within each group, it suffices to find a pair of Markov strategies $\left(\phi_{s}(x), \phi_{b}(x)\right)$ which gives an $n$-tuple composed of $n_{s}$ decision rules $\phi_{s}(x)$ and $n_{b}$ decision rules $\phi_{b}(x)$ that satisfies this property.

In the next section, we characterize a MPNE for this non-cooperative differential game.

\footnotetext{
${ }^{2}$ Clearly, if the right-hand side of (ii) is greater than the right-hand side of (i), then satisfying (ii) satisfies (i); and vice-versa.
} 


\section{Characterization of an equilibrium}

The Hamilton-Jacoby-Bellmann equation (HJB) associated with the problem of firm $k, k=$ $1, \ldots, n$, is

$$
r V_{k}(x)=\underset{q_{k}}{\operatorname{Max}}\left\{\left(a-w_{k}-b\left(q_{k}+\sum_{l \neq k} \phi_{l}(x)\right)\right) q_{k}+V_{k}^{\prime}(x)\left(g(x)-q_{k}-\sum_{l \neq k} \phi_{l}(x)\right)\right\} .
$$

The interior solution to the right-hand side must satisfy ${ }^{3}$

$$
a-w_{k}-2 b q_{k}-b \sum_{l \neq k} \phi_{l}(x)-V_{k}^{\prime}(x)=0 .
$$

Using the symmetry among firms that belong to the same group, we seek to determine a MPNE where firms that belong to the same group have identical strategies. Thus we have

$$
\left(n_{i}+1\right) q_{i}+n_{j} q_{j}=\frac{a-w_{i}-V_{i}^{\prime}(x)}{b}, \quad i, j=b, s, i \neq j .
$$

The solution of this system of two equations in $q_{s}$ and $q_{b}$ expressed in terms of the value functions is given by

$$
q_{i}=\frac{a-w_{i}-V_{i}^{\prime}(x)-n_{j}\left[\left(w_{i}+V_{i}^{\prime}(x)\right)-\left(w_{j}+V_{j}^{\prime}(x)\right)\right]}{b(n+1)}, \quad i, j=b, s, i \neq j
$$

and the total quantity harvested as a function of the value functions can therefore be written

$$
Q=\left(n_{s} q_{s}+n_{b} q_{b}\right)=\frac{n a-n_{s} w_{s}-n_{b} w_{b}-n_{s} V_{s}^{\prime}(x)-n_{b} V_{b}^{\prime}(x)}{b(n+1)} .
$$

The following proposition describes such a MPNE when not all the firms are of the same type.

\footnotetext{
${ }^{3}$ Notice that the right-hand side of the HJB, which is to be maximized with respect to $q_{k}$, is strictly concave in $q_{k}$, its second derivative being $-2 b$.
} 
Proposition 1 Given Assumptions 1 and 2 and strictly positive levels of the stock $\bar{x}_{b}<$ $x_{1 s}<x_{2 s}$, to be defined, then, for any $n_{i} \in\{1, . ., n-1\}$, there exists a MPNE characterized by strategies $\phi_{i}(x), i=s, b$ which satisfy the following properties:

1. over the interval $\left[0, \bar{x}_{b}\right)$, no firm produces;

2. over the interval $\left[\bar{x}_{b}, x_{1 s}\right)$, only the big firms produce;

3. over the interval $\left[x_{1 s}, x_{2 s}\right]$, both types of firms produce using linear strategies;

4. a stock larger than $x_{2 s}$ is not sustainable.

The proof is by construction. We begin by characterizing a MPNE over the subinterval $\left[x_{1 s}, x_{2 s}\right]$. To do this, let

$$
A=-\frac{(n+1)^{2} b}{n^{2}}\left(\delta-\frac{r}{2}\right)<0
$$

and

$$
B_{i}=\frac{\left(\delta-\frac{r}{2}\right)}{n^{2} \delta}\left[\left(n^{2}+1\right)\left(a-w_{i}\right)+n_{j}\left(\frac{2 \delta-\left(n^{2}+1\right) r}{n(\delta-r)}\right)\left(w_{i}-w_{j}\right)\right]
$$

where $i, j=s, b, i \neq j$, and define

$$
x_{1 i}=-\frac{1}{A}\left(\frac{2 \delta-\left(n^{2}+1\right) r}{2 n^{2} \delta}\right)\left[a-w_{i}+n_{j}\left(\frac{(2+n) \delta-r}{n(\delta-r)}\right)\left(w_{i}-w_{j}\right)\right]
$$

and

$$
x_{2 i}=-\frac{B_{i}}{A}
$$

Note that since $A>0$ and $B_{b}>B_{s}>0$ (from Assumption 1 and Assumption 2(i)), we have

$$
x_{1 s}>0 \quad \text { and } \quad x_{1 b}<x_{1 s}<x_{2 s}<x_{2 b} .
$$


Furthermore, from Assumption 2(ii) we have

$$
x_{2 b} \leq \frac{k}{2}
$$

Since $x_{2 b}>x_{2 s}$, this will assure that the interval $\left[x_{1 s}, x_{2 s}\right]$ lies in the increasing part of the growth function $g(x) .{ }^{4}$

We can now prove that the following proposition holds over the interval $\left[x_{1 s}, x_{2 s}\right]$ :

Proposition 2 Let $\phi_{i}(x), i=s, b$, denote the linear harvesting strategies

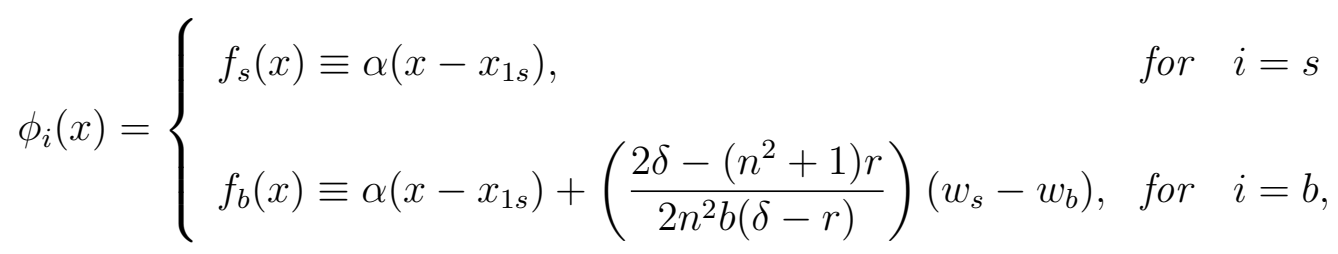

defined over the interval $\left[x_{1 s}, x_{2 s}\right]$ and where

$$
\alpha=\frac{-A}{b(n+1)}=\frac{n+1}{n^{2}}\left(\delta-\frac{r}{2}\right)
$$

and $x_{1 s}$ and $x_{2 s}$ are given respectively by (13) and (14). The $n$-uple $\left(\phi_{s}, \ldots, \phi_{s}, \phi_{b} \ldots, \phi_{b}\right)$ composed of $n_{s}$ strategies $\phi_{s}(x)$ and $n_{b}$ strategies $\phi_{b}(x)$ constitutes a MPNE for the game described in (3) to (5) for $x \in\left[x_{1 s}, x_{2 s}\right]$.

\section{Proof. See Appendix A.}

As shown in Appendix A, the value function that generates the above equilibrium in linear strategies over the interval $\left[x_{1 s}, x_{2 s}\right]$ is quadratic and given by

$$
V_{i}(x)=\frac{A}{2} x^{2}+B_{i} x+C_{i}
$$

\footnotetext{
${ }^{4}$ This avoids having to calculate different linear strategies for the subintervals $\left[x_{1 s}, k / 2\right]$ and $\left(k / 2, x_{2 s}\right]$, without significant loss in insight.
} 
where the coefficients $A$ and $B_{i}$ are given by (11) and (12), and $C_{i}$ is as expressed in the Appendix. Since $A$ is negative, we have $V_{i}^{\prime \prime}(x)<0$ for $i=s, b$. We can see that

$$
q_{s}\left(x_{1 s}\right)=f_{s}\left(x_{1 s}\right)=0 \quad \text { and } \quad V_{s}^{\prime}\left(x_{2 s}\right)=0,
$$

while

$$
q_{b}\left(x_{1 s}\right)=f_{b}\left(x_{1 s}\right)>0 \quad \text { and } \quad V_{b}^{\prime}\left(x_{2 s}\right)>0,
$$

since $x_{2 b}>x_{2 s}$ and $V_{b}^{\prime \prime}(x)<0$.

The aggregate harvesting rate over the interval $\left[x_{1 s}, x_{2 s}\right]$ is $Q(x)=n_{s} f_{s}(x)+n_{b} f_{b}(x)$. By Assumption 2(i), we have

$$
Q^{\prime}(x)=n \alpha>\delta=g^{\prime}(x) \quad \forall x \in\left[x_{1 s}, x_{2 s}\right]
$$

Therefore, there exists a unique steady-state resource stock in the interval $\left[x_{1 s}, x_{2 s}\right]$ and it is stable. It is given by

$$
x^{*}=\left(\frac{1}{n \alpha-\delta}\right)\left\{n \alpha x_{1 s}-n_{b}\left(\frac{2 \delta-\left(n^{2}+1\right) r}{2 n^{2} b(\delta-r)}\right)\left(w_{s}-w_{b}\right)\right\} .
$$

We now consider the characterization of equilibrium strategies for $x \in\left[0, x_{1 s}\right)$. For $x$ in that interval, we will have a corner solution for the $n_{s}$ small firms, since $q_{s}\left(x_{1 s}\right)=0$. Thus only big firms may be active and the problem reduces to finding the equilibrium strategy of the $n_{b}$ big firms over that interval.

Proposition 3 Let $\phi_{i}(x), i=s, b$, denote the strategies

$$
\phi_{s}(x)=0 \quad \text { for } \quad x \in\left[0, x_{1 s}\right)
$$


and

$$
\phi_{b}(x)=\left\{\begin{array}{rll}
0 & \text { for } & x \in\left[0, \bar{x}_{b}\right) \\
h(x) & \text { for } & x \in\left[\bar{x}_{b}, x_{1 s}\right)
\end{array}\right.
$$

where $h(x)$ is a continuous monotone increasing function of $x$, to be defined, which satisfies $h\left(\bar{x}_{b}\right)=0$ and is such that $V_{b}(x)$ is continuously differentiable at $x_{1 s}$ and $\bar{x}_{b}$. The $n$-uple $\left(\phi_{s}, \ldots, \phi_{s}, \phi_{b} \ldots, \phi_{b}\right)$ composed of $n_{s}$ strategies $\phi_{s}(x)$ and $n_{b}$ strategies $\phi_{b}(x)$ constitutes a MPNE for the game described in (3) to (5) for $x \in\left[0, x_{1 s}\right)$.

Proof. Since the right-hand side of the HJBs (6), which is to be maximized with respect to $q_{k}$, is strictly concave in $q_{k}$, and since $q_{s}\left(x_{1 s}\right)=0$, it follows that we have a corner solution for the small firms for all $x \in\left[0, x_{1 s}\right)$. Therefore $\phi_{s}(x)=0$ over the interval being considered, as stated in the proposition.

There remains to determine an equilibrium strategy for the big firms. This will involve finding a $\bar{x}_{b}$ such that $\phi_{b}\left(\bar{x}_{b}\right)=0$, with $V_{b}(x)$ continuously differentiable in the neighborhood of $x_{1 s}$. Given that $q_{s}(x)=0$ for all $x \in\left[0, x_{1 s}\right)$, and using the symmetry of the firms within the group, an interior solution to the right-hand of the HJB (6) of the typical firm of type $b$ requires

$$
a-w_{b}-\left(n_{b}+1\right) b \phi_{b}(x)-V_{b}^{\prime}(x)=0 .
$$

It follows that

$$
\phi_{b}(x)=\frac{a-w_{b}-V_{b}^{\prime}(x)}{\left(n_{b}+1\right) b} .
$$

Substituting into the HJB gives

$$
r V_{b}(x)=\left(\frac{a-w_{b}-n_{b}^{2} V_{b}^{\prime}(x)}{n_{b}+1}\right)\left(\frac{a-w_{b}-V_{b}^{\prime}(x)}{\left(n_{b}+1\right) b}\right)+\delta V_{b}^{\prime}(x) x .
$$


The requirement that $\phi_{b}\left(\bar{x}_{b}\right)=0$ means that

$$
V_{b}^{\prime}\left(\bar{x}_{b}\right)=a-w_{b}
$$

The solution to such a differential equation can be characterized implicitly. Letting $p=V_{b}^{\prime}(x)$, we have $\frac{d p}{d x}=V_{b}^{\prime \prime}(x)$. Then, differentiating the differential equation (22) with respect to $x$ gives

$$
(r-\delta) p \frac{d x}{d p}-\delta x=\left(\frac{2 n_{b}^{2}}{\left(n_{b}+1\right)^{2} b}\right) p-\frac{\left(a-w_{b}\right)\left(n_{b}^{2}+1\right)}{\left(n_{b}+1\right)^{2} b}
$$

The general solution to this first-order differential equation in $x$ is

$$
x(p)=C_{1} p^{\frac{-\delta}{\delta-r}}-\left(\frac{2 n_{b}^{2}}{(2 \delta-r) b\left(n_{b}+1\right)^{2}}\right) p+\left(\frac{\left(a-w_{b}\right)\left(n_{b}^{2}+1\right)}{\delta b\left(n_{b}+1\right)^{2}}\right)
$$

where $C_{1}$ is the arbitrary constant. In order to guarantee that $V_{b}(x)$ is continuously differentiable at $x_{1 s}$ this constant is chosen such that at $x=x_{1 s}$ we have $p=\lim _{x \rightarrow x_{1 s}^{+}} V_{b}^{\prime}(x)$. In other words, $C_{1}$ is determined implicitly by

$$
x\left(V_{b}^{\prime}\left(x_{1 s}\right)^{+}\right)=x_{1 s},
$$

where $V_{b}^{\prime}\left(x_{1 s}\right)^{+}=\lim _{x \rightarrow x_{1 s}^{+}} V_{b}^{\prime}(x)$ is obtained from the solution over the interval $\left[x_{1 s}, x_{2 s}\right]$ given by Proposition 2 .

As for the value of $\bar{x}_{b}$, it must satisfy $V_{b}^{\prime}\left(\bar{x}_{b}\right)=a-w_{b}$, and hence $p=a-w_{b}$. It is therefore given implicitly by

$$
x\left(a-w_{b}\right)=\bar{x}_{b} .
$$

Once the value of $\bar{x}_{b}$ determined we obtain $V\left(\bar{x}_{b}\right)$ from $(22)$ and the value function $V_{b}(x)$ over $\left[0, \bar{x}_{b}\right)$. It can be checked that value function $V_{b}(x)$ is continuously differentiable in the neighborhood of $\bar{x}_{b}$. That the harvesting rate of the big firms is a continuous monotone 
increasing function of $x$ for $x \in\left[\bar{x}_{b}, x_{1 s}\right)$ follows directly from (21), since we have $x^{\prime}(p)<0$ and hence $\frac{d p}{d x}=V_{b}^{\prime \prime}(x)<0$. Furthermore, since $x^{\prime \prime}(p)>0$, it is a strictly convex function of $x$.

From (17), we have that the value function from which the solution in linear strategies over the interval $\left[x_{1 s}, x_{2 s}\right]$ was obtained is, for the firms of type $b$,

$$
V_{b}(x) \equiv \frac{A}{2} x^{2}+B_{b} x+C_{b}
$$

and therefore

$$
V_{b}^{\prime}\left(x_{1 s}\right)^{+}=A x_{1 s}+B_{b} .
$$

Substituting for $A, B_{b}$ and $x_{1 s}$, we find that

$$
V_{b}^{\prime}\left(x_{1 s}\right)^{+}=a-w_{b}+b\left(n_{b}+1\right) f_{b}\left(x_{1 s}\right),
$$

where, from Proposition 2,

$$
f_{b}\left(x_{1 s}\right)=\left(\frac{2 \delta-\left(n^{2}+1\right) r}{2 n^{2} b(\delta-r)}\right)\left(w_{s}-w_{b}\right) .
$$

This is the production of the typical big firm when $x=x_{1 s}$ under the equilibrium linear strategies for the interval $\left[x_{1 s}, x_{2 s}\right]$. The left-hand and right-hand derivatives of $V_{b}(x)$ at $x=x_{1 s}$ must be equal to assure the requirement that it be continuously differentiable. Therefore, substituting the value of $V_{b}^{\prime}\left(x_{1 s}\right)^{+}$into (21) we can see that the harvesting rate of the big firms is continuous at $x_{1 s}$, with no jump occurring.

There remains to consider $x>x_{2 s}$. For that purpose, we can state the following:

Proposition 4 Conditional on the linear strategies described in Proposition 2 being adopted over the interval $\left[x_{1 s}, x_{2 s}\right]$, there exists a candidate for equilibrium which is such that, if $x>x_{2 s}$, the small firms bring down the resource stock to $x_{2 s}$ by impulse control, with the 
result that a stock greater than $x_{2 s}$ is not sustainable.

Proof. First note that

$$
q_{i}^{S C}=\frac{a-\left(n_{i}+1\right) w_{i}+n_{j} w_{j}}{b(n+1)}, \quad i, j=b, s, i \neq j
$$

are the equilibrium quantities which would be produced in an equivalent static Cournot game, where the input (the resource being harvested) is considered abundant. The corresponding total quantity is

$$
Q^{S C}=\frac{n a-n_{s} w_{s}-n_{b} w_{b}}{b(n+1)} .
$$

Making use of (18) and (19), we get from (9) and (10)

$$
\begin{aligned}
& q_{b}\left(x_{2 s}\right)=q_{b}^{S C}-\frac{\left(n_{s}+1\right) V_{b}^{\prime}\left(x_{2 s}\right)}{(n+1) b}<q_{b}^{S C} \\
& q_{s}\left(x_{2 s}\right)=q_{s}^{S C}+\frac{n_{b} V_{b}^{\prime}\left(x_{2 s}\right)}{(n+1) b}>q_{s}^{S C}
\end{aligned}
$$

and

$$
Q\left(x_{2 s}\right)=Q^{S C}-\frac{n_{b} V_{b}^{\prime}\left(x_{2 s}\right)}{b(n+1)}<Q^{S C} .
$$

Notice that if $n_{b}=0$, so that $n=n_{s}$, then $q_{s}\left(x_{2 s}\right)=q_{s}^{S C}$ and $Q\left(x_{2 s}\right)=Q^{S C}$. We then have the identical-firms situation analyzed in Benchekroun (2003), where, for $x \geq x_{2 s}$, the firms play the static Cournot equilibrium forever, reaching a stable steady state in the decreasing part of the growth function. ${ }^{5}$

When the firms are not identical, if the initial stock were sufficiently large, namely some $x \geq Q^{S C} / \delta$, and if $Q^{S C}<\delta k / 2\left(\equiv \max _{x} g(x)\right)$, the firms could still play the static Cournot equilibrium forever, since the stock would then converge to a stable steady state along the

\footnotetext{
${ }^{5}$ The same is also true if instead $n_{s}=0$ so that $q_{b}\left(x_{2 b}\right)=q_{b}^{S C}$ and $Q\left(x_{2 b}\right)=Q^{S C}$. In Benchekroun (2003) $w_{s}=w_{b}=0$, so that the distinction is irrelevant.
} 
downward sloping part of the growth function, as in the identical-firm context. The static Cournot equilibrium still qualifies as a potential MPNE for $x>x_{2 s}$. Each firm's discounted sum of payoffs would then be

$$
\frac{\pi_{k}^{S C}}{r} \equiv \frac{\left.\left[a-w_{k}-b Q^{S C}\right)\right] q_{k}^{S C}}{r} \quad \text { for } \quad k=b, s
$$

with $Q^{S C}$ and $q_{k}^{S C}$ and given by (23), (24) and (25).

For the small firms, this payoff is smaller than what they can earn if the stock is at $x_{2 s}$ with the firms playing the equilibrium in linear strategies of the interval $\left[x_{1 s}, x_{2 s}\right]$. The small firms would then each be producing more than in the static Cournot equilibrium, while total production would be smaller and hence the market price higher. Indeed, using the fact that $V_{s}^{\prime}\left(x_{2 s}\right)=0$, we get from (6) that the HJB for the typical small firm evaluated at $x_{2 s}$ is

$$
r V_{s}\left(x_{2 s}\right)=\left[a-w_{s}-b Q\left(x_{2 s}\right)\right] q_{s}\left(x_{2 s}\right) \equiv \pi_{s}
$$

From (25) and (26) we have $\pi_{s}>\pi_{s}^{S C}$ and hence

$$
V_{s}\left(x_{2 s}\right)=\frac{\pi_{s}}{r}>\frac{\pi_{s}^{S C}}{r}
$$

Therefore, for any $x>x_{2 s}$, given that the big firms play their static Cournot strategy, it is in the small firms' interest to instantaneously reduce the stock to $x_{2 s}$, through an impulse control, so as to have the firms play the equilibrium in linear strategies of Proposition 2 instead of the static Cournot equilibrium. As for the big firms, given that the small firms adopt a harvest rate that maintains $x_{2 s}$, playing their static Cournot output for any $x>x_{2 s}$ leaves them no worst off. Hence, neither type of firms has an incentive to unilaterally deviate. As a result, a stock greater than $x_{2 s}$ is not sustainable in this MPNE.

Notice that the small firms would not allow the stock to grow beyond $x_{2 s}$ even in the case where the big firms continue to follow their linear strategy defined in Proposition 2 for $\left[x_{1 s}, x_{2 s}\right]$, since $V_{s}^{\prime}\left(x_{2 s}\right)=0$ and $V_{s}^{\prime \prime}(x)<0$ for $x>x_{2 s}$, which means that following the 
equilibrium in linear strategy for $x>x_{2 s}$ implies for the small firms a smaller payoff than $V_{s}\left(x_{2 s}\right)$.

Notice also that if the small firms adopt a strategy for $x>x_{2 s}$ that prescribes an impulse control that instantly brings the stock to $x_{2 s}$, then the big firms' extraction for $x>x_{2 s}$ is not payoff relevant. In particular, their best response over $\left(x_{2 s}, \infty\right)$ to that strategy by the small firms could include a continuation of their linear strategy defined in Proposition 2 for $\left[x_{1 s}, x_{2 s}\right]$, as well as playing the static Cournot quantity.

If the initial stock is sufficiently large but $Q^{S C}>\delta k / 2$, then the static Cournot equilibrium cannot be played forever, since the stock would be decreasing. In that case, the stock would reach $x_{2 s}$ in finite time; again $x>x_{2 s}$ is not sustainable.

Since the firms will be playing the linear strategies of Proposition 2 for $x \in\left[x_{1 s}, x_{2 s}\right]$, the stock will converge to the stable steady state $x^{*}$ given by $(20)$.

Notice that the result of Proposition 4 is conditional on the equilibrium in linear strategies being played over the interval $\left[x_{1 s}, x_{2 s}\right]$. This means that, contrary to the identical-firms case of Benchekroun (2003), playing the static Cournot equilibrium for $x>x_{s}$ is not sustainable in the presence of the slightest cost-differentiation among firms, if the equilibrium in linear strategies is played over the interval $\left[x_{1 s}, x_{2 s}\right]$. It follows that if there exists a MPNE with the property that the static Cournot equilibrium is played forever beyond some level of the stock, then it must be the case that this is preceded by an interval over which non-linear strategies are played. Such an equilibrium should also have the property that both types of firms would reach a maximum of their respective value function at the level of stock at which the static Cournot strategies set in. This is not the case of the equilibrium in linear strategies over $\left[x_{1 s}, x_{2 s}\right]$ posited in Proposition 4 , since $V_{b}^{\prime}\left(x_{2 s}\right)>0$.

Taking for granted that the linear strategies of Proposition 2 are played over the interval $\left[x_{1 s}, x_{2 s}\right]$, there may well exist other types of equilibria for which $x>x_{2 s}$ is sustainable. To see this, let $\tilde{x}$ denote a steady state in the decreasing part of the growth function which can be supported by a MPNE for $x>x_{2 s}$. Let $W(x)$ denote the corresponding value function, with $V(x)$ representing the quadratic value function (17) over the interval $\left[x_{1 s}, x_{2 s}\right]$, and let 
$p(x)=a-b Q(x)$. Then we can write

$$
\begin{aligned}
\pi_{s}\left(x_{2 s}\right)-\pi_{s}(\tilde{x}) & =\left[p\left(x_{2 s}\right)-w_{s}\right] q_{s}\left(x_{2 s}\right)-\left[p(\tilde{x})-w_{s}\right] q_{s}(\tilde{x}) \\
& =\left[p\left(x_{2 s}\right)-w_{s}\right]\left[q_{s}\left(x_{2 s}\right)-q_{s}(\tilde{x})\right]+b\left[Q(\tilde{x})-Q\left(x_{2 s}\right)\right] q_{s}(\tilde{x})
\end{aligned}
$$

From (9) and (10) and the fact that $V_{s}^{\prime}\left(x_{2 s}\right)=0$, we know that

$$
q_{s}\left(x_{2 s}\right)-q_{s}(\tilde{x})=\frac{n_{b} V_{b}^{\prime}\left(x_{2 s}\right)}{(n+1) b}-\frac{n_{s} W_{s}^{\prime}(\tilde{x})+n_{b} W_{b}^{\prime}(\tilde{x})}{(n+1) b}+\frac{W_{s}^{\prime}(\tilde{x})}{b}
$$

and

$$
Q(\tilde{x})-Q\left(x_{2 s}\right)=\frac{n_{b} V_{b}^{\prime}\left(x_{2 s}\right)}{(n+1) b}-\frac{n_{s} W_{s}^{\prime}(\tilde{x})+n_{b} W_{b}^{\prime}(\tilde{x})}{(n+1) b}
$$

where it can be assumed that $W_{i}^{\prime} \geq 0, i=s, b$, for, if $W_{i}^{\prime}<0$, firms of type $i$ could increase their profits by destroying some of the stock. Substituting in the above yields

$$
\pi_{s}\left(x_{2 s}\right)-\pi_{s}(\tilde{x})=\left[p\left(x_{2 s}\right)-w_{s}\right] \frac{W_{s}^{\prime}(\tilde{x})}{b}+\left[p\left(x_{2 s}\right)-w_{s}+b q_{s}(\tilde{x})\right]\left[Q(\tilde{x})-Q\left(x_{2 s}\right)\right]
$$

We can see that the sign of $\pi_{s}\left(x_{2 s}\right)-\pi_{s}(\tilde{x})$ depends crucially on the sign of $Q(\tilde{x})-Q\left(x_{2 s}\right)$. If $Q(\tilde{x})-Q\left(x_{2 s}\right) \geq 0$, then $\pi_{s}\left(x_{2 s}\right)-\pi_{s}(\tilde{x})>0$, in which case there will be an impulse control by firms $s$ to maintain $x_{2 s}$. The static Cournot falls in this category, since it implies $W_{i}^{\prime}(\tilde{x})=0$, and hence $Q(\tilde{x})-Q\left(x_{2 s}\right)>0$. However, we cannot exclude the existence of equilibria for which $\pi_{s}\left(x_{2 s}\right)-\pi_{s}(\tilde{x})<0$. If such equilibria exist we would necessarily observe that $Q(\tilde{x})-Q\left(x_{2 s}\right)<0$ and there would be no incentive to maintain $x_{2 s}$.

Remark: It is interesting to note that we have $V_{s}\left(x_{2 s}\right)=\frac{\pi_{s}}{r}>\frac{\pi_{s}^{S C}}{r}$. and $q_{s}\left(x_{2 s}\right)>q_{s}^{S C}$ (see 27 and 25 in the proof of Proposition 4). The small firms can earn a larger payoff than they woull earn in an equivalent static Cournot game where the input is considered abundant (i.e., in the absence of renewability constraint). 


\section{Conclusion}

Asymmetries among economic agents exploiting in common stocks of natural resources are very frequently encountered. In spite of that fact, they are practically ignored in the literature on the economics of common pool resources. A reason for this is arguably that dealing with asymmetries considerably increases the difficulties of characterizing the equilibria, particularly in the context of a dynamic oligopolistic game. An important conclusion to be drawn from this paper is that it would be a mistake to assume that the nature of the equilibria found in the symmetric situation can be replicated in an asymmetric context. At the very least, great caution should be exercised, since an equilibrium that holds in the symmetric case may not be robust to the introduction of the slightest heterogeneity among the agents.

Indeed, we have shown that the introduction of cost heterogeneity among agents can have a drastic effect on the nature of equilibrium that can be supported, as compared to the homogeneous agents case. The benchmark case was taken to be one in which a common pool of a renewable resource is harvested by identical agents and where a MPNE exists with the following properties: below some initial threshold level of the resource stock, the resource is not harvested at all, hence allowing the resource to grow; follows an interval of the stock, up to some second threshold, over which each agents's harvesting decision is a linear and increasing function of the resource stock; beyond that last threshold, each agents's harvest rate is a constant that corresponds to the static Cournot equilibrium. It was shown here that if the agents are instead divided between low and high marginal costs ones, keeping other things the same, playing the static Cournot strategies beyond some endogenously determined interval of the stock over which linear strategies are played is not sustainable as an equilibrium. The reason for this is that for stock levels greater than the upper bound of the interval over which the linear strategies are played, the agents with the higher marginal cost can earn a larger payoff by bringing back the stock to that upper bound via an impulse control; hence stock levels greater than that upper bound are not sustainable in this equilibrium. We do show that acting in this way constitutes a MPNE, which we fully 
characterize. An interesting feature of this equilibrium is that the high cost agents can earn a larger payoff than they would earn in an equivalent static Cournot game with unlimited renewability of the resource as an input.

It can of course not be ruled out that other MPNE exist such that linear strategies are played over some interval of the stock, while higher stock levels remain sustainable. Showing their existence and characterizing such equilibria remains a challenging task for future research. One thing is clear however: if there exists a MPNE in the asymmetric case analyzed here such that static Cournot strategies are played beyond some stock threshold, it must be the case that in the interval preceding that threshold non-linear strategies have been played, in sharp contrast with the symmetric case. 


\section{Appendix}

\section{A Proof of Proposition 2}

We need to solve the problem of firm $k, k=1, \ldots, n$, as stated in (3) to (5). This will determine its best response, over the interval $\left[x_{1 s}, x_{2 s}\right]$, to the strategies $\phi_{i}(x)$ of the $n-1$ other firms resulting from the MPNE proposed in Proposition 2.

Substituting for $q_{s}$ and $q_{b}$ from (9) into the HJB (6) of each type of firm, we obtain the following non-linear system of differential equations in $\left(V_{b}(S), V_{s}(S)\right)$ :

$$
r V_{k}(x)=\left(a-w_{k}-b\left(n_{s} q_{s}+n_{b} q_{b}\right)\right) q_{k}+V_{k}^{\prime}(x)\left(\delta x-\left(n_{s} q_{s}+n_{b} q_{b}\right)\right), \quad k=b, s
$$

where $q_{s}$ and $q_{b}$ are given by (9). Recall that, by Assumption 2(ii), the interval $\left[x_{1 s}, x_{2 s}\right]$ lies in the increasing part of the growth function, for which $g(x)=\delta x$.

Given the linear-quadratic structure of the game over the interval being considered, we search for quadratic value functions of the form

$$
V_{k}=\frac{A_{k}}{2} x^{2}+B_{k} x+C_{k}, \quad k=b, s
$$

where $A_{k}, B_{k}$ and $C_{k}$ are parameters to be determined.

If we rewrite the HJBs using this form of the value function we get, for $i, j=s, b, i \neq j$,

$$
\begin{aligned}
& \left\{b(n+1)^{2} A_{i}\left(\delta-\frac{r}{2}\right)+\left(n_{i} A_{i}+n_{j} A_{j}\right)^{2}\right\} x^{2} \\
& +\left\{b(n+1)^{2} B_{i}(\delta-r)-A_{i}\left[\left(n^{2}+1+2 n_{j}\right)\left(a-w_{i}\right)+2 n_{i} n_{j}\left(w_{i}-w_{j}\right)\right]\right. \\
& \left.+2 n_{j} A_{j}\left[\left(a-w_{i}\right)-n_{j}\left(w_{i}-w_{j}\right)\right]+2\left(n_{i} A_{i}+n_{j} A_{j}\right)\left(n_{i} B_{i}+n_{j} B_{j}\right)\right\} x \\
& +\left[\left(a-w_{i}\right)-n_{j}\left(w_{i}-w_{j}\right)\right]^{2}-B_{i}\left[\left(n^{2}+1+2 n_{j}\right)\left(a-w_{i}\right)+2 n_{i} n_{j}\left(w_{i}-w_{j}\right)\right] \\
& +2 n_{j} B_{j}\left[\left(a-w_{i}\right)-n_{j}\left(w_{i}-w_{j}\right)\right]+\left(n_{i} B_{i}+n_{j} B_{j}\right)^{2}-(n+1)^{2} b r C_{i} \\
& =0
\end{aligned}
$$


Since this second degree polynomial must hold for all $x \in\left[x_{1 s}, x_{2 s}\right]$, all its coefficients must be set to zero. Doing so gives us a solution for the unknowns $A_{i}, B_{i}$ and $C_{i}$, namely

$$
\begin{aligned}
& A_{i}=A_{j}=A=-\frac{(n+1)^{2} b}{n^{2}}\left(\delta-\frac{r}{2}\right) \\
& B_{i}=\frac{\left(\delta-\frac{r}{2}\right)}{n^{2} \delta}\left[\left(n^{2}+1\right)\left(a-w_{i}\right)+n_{j}\left(w_{i}-w_{j}\right) \frac{\left[2 \delta-\left(n^{2}+1\right) r\right]}{n(\delta-r)}\right]
\end{aligned}
$$

and

$$
\begin{aligned}
C_{i}= & \frac{1}{(n+1)^{2} b r}\left\{\left[\left(a-w_{i}\right)-n_{j}\left(w_{i}-w_{j}\right)\right]^{2}+\left(n_{i} B_{i}+n_{j} B_{j}\right)^{2}\right. \\
& \left.-\left(a-w_{i}\right)\left[\left(n^{2}+1\right) B_{i}+2 n_{j}\left(B_{i}-B_{j}\right)\right]-2 n_{j}\left(w_{i}-w_{j}\right)\left(n_{i} B_{i}+n_{j} B_{j}\right)\right\}
\end{aligned}
$$

Taking into account the fact that we must have $A_{s}=A_{b}=A$, write

$$
V_{i}(x) \equiv \frac{A}{2} x^{2}+B_{i} x+C_{i}, \quad i=b, s .
$$

and define

$$
f_{i}(x) \equiv \frac{1}{b(n+1)}\left[-A x+\left(a-w_{i}-B_{i}\right)-n_{j}\left(w_{i}-w_{j}+B_{i}-B_{j}\right)\right], \quad i, j=b, s, i \neq j .
$$

The stock levels $x_{1 i}$ are those for which $f_{i}(x)=0$, that is

$$
\begin{aligned}
x_{1 i} & =\frac{1}{-A}\left[B_{i}-\left(a-w_{i}\right)+n_{j}\left(B_{i}-B_{j}+w_{i}-w_{j}\right)\right] \\
& =\frac{1}{-A}\left(\frac{2 \delta-\left(n^{2}+1\right) r}{2 n^{2} \delta}\right)\left[a-w_{i}+n_{j}\left(\frac{(2+n) \delta-r}{n(\delta-r)}\right)\left(w_{i}-w_{j}\right)\right] .
\end{aligned}
$$

We may therefore write

$$
f_{i}(x) \equiv \frac{-A}{b(n+1)}\left[x-x_{1 i}\right]=\alpha\left(x-x_{1 i}\right),
$$


and

$$
\begin{aligned}
f_{b}(x)-f_{s}(x) & =\frac{A}{b(n+1)}\left[x_{1 b}-x_{1 s}\right] \\
& =\left(\frac{2 \delta-\left(n^{2}+1\right) r}{2 n^{2} b(\delta-r)}\right)\left(w_{s}-w_{b}\right)
\end{aligned}
$$

It immediately follows that

$$
f_{s}(x)=\alpha\left(x-x_{1 s}\right)
$$

and

$$
f_{b}(x)=\alpha\left(x-x_{1 s}\right)+\left(\frac{2 \delta-\left(n^{2}+1\right) r}{2 n^{2} b(\delta-r)}\right)\left(w_{s}-w_{b}\right)
$$

as stated in the proposition.

The stock level $x_{2 s}$, which defines the upper bound of the interval considered, is the one that maximizes $V_{s}(x)$ and hence given by $V_{s}^{\prime}\left(x_{2 s}\right)=0$, or

$$
x_{2 s}=-\frac{B_{s}}{A} .
$$

We can similarly determine the stock level $x_{2 b}$ as that which satisfies $V_{b}^{\prime}\left(x_{2 b}\right)=0$, that is $x_{2 b}=-B_{b} / A$. It lies outside the interval $\left[x_{1 s}, x_{2 s}\right]$, since $x_{2 b}>x_{2 s}$, as does $x_{1 b}$, since $x_{1 b}<x_{1 s}$. 


\section{References}

Benchekroun, Hassan (2003) 'Unilateral production restrictions in a dynamic duopoly.' Journal of Economic Theory 111, 214-239

_ (2008) 'Comparative dynamics in a productive asset oligopoly.' Journal of Economic Theory $138,237-261$

Clemhout, S., and H. Y. Wan (1985) 'Dynamic common property resources and environmental problems.' Journal of Optimization Theory and Applications 46, 471-481

Dockner, E., and G. Sorger (1996) 'Existence and properties of equilibria for a dynamic game on productive assets.' Journal of Economic Theory 71, 209-227

Dockner, E., S. Jorgensen, N. V. Long, and G. Sorger (2000) Differential Games in Economics and Management Science (Cambridge: Cambridge University Press)

Dutta, P.K., and R.K. Sundaram (1993a) 'The tragedy of the commoncs.' Economic Theory $3,413-426$

_ (1993b) 'How different can strategic models be?' Journal of Economic Theory 60, 42-61

Fischer, R., and L. J. Mirman (1992) 'Strategic dynamic interactions: Fish wars.' Journal of Economic Dynamics and Control 16, 267-287

_ (1996) 'The compleat fish wars: Biological and dynamic interactions.' Journal of Environmental Economics and Management 30, 34-42

Gaudet, G., and H. Lohoues (2008) 'On limits to the use of linear markov strategies in common property natural resource games.' Environmental Modeling and Assessment 13, 567574

Karp, L. (1992) 'Social welfare in a common property oligopoly.' International Economic Review 33, 353-372

Levhari, D., and L. J. Mirman (1980) 'The great fish war: An example using a dynamic cournot-nash solution.' Bell Journal of Economics 11, 322-334

Mason, C., and S. Polasky (1997) 'The optimal number of firms in the commons: A dynamic approach.' Canadian Journal of Economics 30, 1143-1160

Ostrom, E., and R. Gardner (1993) 'Coping with asymmetries in the commons: Selfgoverning irrigation systems can work.' The Journal of Economic Perspectives 7(4), 93-112

Plourde, C., and D. Yeung (1989) 'Harvesting of a transboundary replenishable fish stock: A noncooperative solution.' Marine Resource Economics 6, 57-70 


\section{Récents cahiers de recherche du CIREQ Recent Working Papers of CIREQ}

Si vous désirez obtenir des exemplaires des cahiers, vous pouvez les télécharger à partir de notre site Web http://www.cireqmontreal.com/cahiers-de-recherche

If you wish to obtain copies of the working papers, you can download them directly from our website, http://www.cireqmontreal.com/cahiers-de-recherche

13-2011 Ehlers, L., I.E. Hafalir, M. Bumin Yenmez, M.A. Yildirim, "School Choice with Controlled Choice Constraints : Hard Bounds versus Soft Bounds", novembre 2011, 43 pages

14-2011 Sprumont, Y., "Constrained-Optimal Strategy-Proof Assignment : Beyond the Groves Mechanisms", décembre 2011, 18 pages

01-2012 Long, N.V., V. Martinet, "Combining Rights and Welfarism : A New Approach to Intertemporal Evaluation of Social Alternatives", janvier 2012, 43 pages

02-2012 Atewamba, C., G. Gaudet, "Pricing of Durable Nonrenewable Natural Resources under Stochastic Investment Opportunities", novembre 2011, 24 pages

03-2012 Ehlers, L., "Top Trading with Fixed Tie-Breaking in Markets with Indivisible Goods", mars 2012, 25 pages

04-2012 Andersson, T., L. Ehlers, L.-G. Svensson, "(Minimally) $\epsilon$-Incentive Compatible Competitive Equilibria in Economies with Indivisibilities", avril 2012, 13 pages

05-2012 Bossert, W., H. Peters, "Single-Plateaued Choice", mai 2012, 15 pages

06-2012 Benchekroun, H., G. Martín-Herrán, "Farsight and Myopia in a Transboundary Pollution Game", juillet 2012, 19 pages

07-2012 Bossert, W., L. Ceriani, S.R. Chakravarty, C. D'Ambrosio, "Intertemporal Material Deprivation", juin 2012, 21 pages

08-2012 Bossert, W., Qi, C.X., J.A. Weymark, "Extensive Social Choice and the Measurement of Group Fitness in Biological Hierarchies", juillet 2012, 25 pages

09-2012 Bossert, W., K. Suzumura, "Multi-Profile Intertemporal Social Choice", juillet 2012, 20 pages

10-2012 Bakis, O., B. Kaymak, "On the Optimality of Progressive Income Redistribution", août 2012, 42 pages

11-2012 Poschke, M., "The Labor Market, the Decision to Become an Entrepreneur, and the Firm Size Distribution", août 2012, 29 pages

12-2012 Bossert, W., Y. Sprumont, "Strategy-proof Preference Aggregation", août 2012, 23 pages

13-2012 Poschke, M., "Who Becomes an Entrepreneur? Labor Market Prospects and Occupational Choice", septembre 2012, 49 pages 